\title{
Ruminal parameters and fatty acid composition of omasal digesta and milk in cows fed sugarcane-based diets supplemented with sunflower oil
}

\section{Parâmetros ruminais e perfil de ácidos graxos da digesta omasal e do leite de vacas alimentadas com dietas à base de cana de açúcar suplementadas com óleo de girassol}

\author{
Fernando César Ferraz Lopes ${ }^{*}$; Shirley Motta de Souza²; Sebastião de Campos \\ Valadares Filho ${ }^{3}$; Marco Antônio Sundfeld da Gama ${ }^{4}$; Luciana Navajas Rennó ${ }^{3}$
}

\section{Highlights:}

Intake, digestibility and rumen degradability of DM and fiber were unchanged by sunflower oil.

Moderate sunflower oil levels promoted milk fat depression in cows receiving sugarcane-based diets.

Nutritional quality of milk fat was improved by sunflower oil in sugarcane-based diets.

\begin{abstract}
This study evaluates the intake and digestion of nutrients, parameters of rumen fermentation and degradation, omasal digesta and milk fatty acid composition, productive performance, and the concentration of serum metabolites in cows fed $600 \mathrm{~g} \mathrm{~kg}^{-1}$ sugarcane-based diets containing 0 (control), 15,30 , and $45 \mathrm{~g} \mathrm{~kg}^{-1}$ sunflower oil (SO) on a dry matter (DM) basis. Four rumen-cannulated Holstein $\mathrm{x}$ Gyr cows yielding $15 \pm 5 \mathrm{~kg}$ day ${ }^{-1}$ with $110 \pm 10$ days in milk were allocated in a $4 \mathrm{x} 4$ Latin square design. Data were analyzed using mixed models, and significant differences were declared at $\mathrm{P}<0.05$. There was no effect of SO on the intake and apparent digestibility of DM, crude protein, neutral detergent fiber (NDF) and nonfibrous carbohydrates, but there was a linear increase in the intake and digestibility of ether extract. Dietary SO levels did not alter the ruminal degradability parameters for DM and NDF, rumen $\mathrm{pH}$ and contents of ammonia $\mathrm{N}$, acetate, propionate and volatile fatty acids. Milk fat content and yield were linearly decreased, whereas a linear increase in milk protein content was observed in response to increasing levels of SO, but with no effect on milk yield. Linear reductions in palmitic and $\alpha$-linolenic acid contents, a linear increase in trans-10 C18:1 and elaidic acids, and a quadratic effect on vaccenic and rumenic acids were observed in omasal digesta of cows fed increasing levels of SO. Overall, up to $45 \mathrm{~g} \mathrm{~kg}^{-1} \mathrm{SO}$ can be included on DM of chopped sugarcane-based diets without reducing consumption, apparent digestibility and rumen degradability of DM and fiber. Supplementing chopped sugarcanebased diets with 30 to $45 \mathrm{~g} \mathrm{~kg}^{-1} \mathrm{SO}$ (DM basis) promotes milk fat depression due to the inhibition of mammary lipogenesis by specific rumen-derived fatty acid intermediates of the biohydrogenation of unsaturated $\mathrm{C} 18$ fatty acids. The inclusion of 15 to $45 \mathrm{~g} \mathrm{~kg}^{-1} \mathrm{SO}$ in chopped sugarcane-based diets improves the nutritional quality of milk fat, with increases in the levels of oleic, vaccenic and rumenic acids, beneficial to human health, and a reduction in the levels of the hypercholesterolemic lauric, myristic and palmitic acids.
\end{abstract}

Key words: Conjugated linoleic acid. Rumenic acid. Saccharum officinarum. Vaccenic acid.

\footnotetext{
${ }^{1}$ Analista, Empresa Brasileira de Pesquisa Agropecuária, EMBRAPA Gado de Leite, Juiz de Fora, MG, Brasil. E-mail: fernando. lopes@embrapa.br

2 Prof $^{a}$ Dr $^{\mathrm{a}}$, Instituto Federal do Sul de Minas Gerais, IFSULDEMINAS, Campus Machado, Machado, MG, Brasil. E-mail: motta. shirley@hotmail.com

3 Profs. Drs., Departamento de Zootecnia, Universidade Federal de Viçosa, UFV, Viçosa, MG, Brasil. E-mail: scvfilho@ufv.br; lnrenno@hotmail.com

4 Pesquisador, EMBRAPA Gado de Leite, Juiz de Fora, MG, Brasil. E-mail: marco.gama@embrapa.br

* Author for correspondence
} 


\section{Resumo}

O objetivo deste estudo foi avaliar o consumo e a digestão dos nutrientes, os parâmetros de fermentação e degradação ruminal, o perfil de ácidos graxos da digesta omasal e do leite, o desempenho produtivo e as concentrações séricas de metabólitos em vacas alimentadas com dietas à base de $600 \mathrm{~g} \mathrm{~kg}^{-1}$ de cana de açúcar com 0 (controle), 15, 30 e $45 \mathrm{~g} \mathrm{~kg}^{-1}$ de óleo de girassol (OG) na base da matéria seca (MS). Foram utilizadas quatro vacas Holandês x Gir com $110 \pm 10$ dias em lactação, produzindo $15 \pm 5 \mathrm{~kg} \mathrm{dia}^{-1}$ de leite, canuladas no rúmen, e alocadas em delineamento Quadrado Latino 4 x 4 . Os resultados foram analisados por modelos mistos e efeitos considerados significativos quando $\mathrm{P}<0,05$. Não houve efeito do OG no consumo e digestibilidade aparente da MS, proteína bruta, fibra em detergente neutro (FDN) e carboidratos não fibrosos, mas houve aumento linear no consumo e digestibilidade aparente do extrato etéreo. Não houve efeito do OG sobre os parâmetros de degradabilidade da MS e FDN, sobre o pH do rúmen nem sobre as concentrações ruminais de $\mathrm{N}$ amoniacal, acetato, propionato e ácidos graxos voláteis totais. O OG promoveu redução linear no teor e na produção de gordura do leite, aumento linear no teor de proteína do leite, mas não houve efeito sobre a produção de leite. Na digesta omasal, o OG promoveu reduções lineares nos teores dos ácidos palmítico e $\alpha$-linolênico, aumentos lineares nos teores dos ácidos elaídico e C18:1 trans-10, e efeito quadrático nos teores dos ácidos vacênico e rumênico. Concluindo, até $45 \mathrm{~g} \mathrm{~kg}^{-1}$ de OG pode ser incluído na MS de dietas à base de cana de açúcar picada, sem reduzir o consumo, a digestibilidade aparente a degradabilidade ruminal da MS e da fibra. A suplementação da MS de dietas à base de cana de açúcar picada com $30 \mathrm{a} 45 \mathrm{~g} \mathrm{~kg}^{-1}$ de óleo de girassol promove redução no teor de gordura do leite, devido à inibição da lipogênese mamária por específicos ácidos graxos formados no rúmen a partir da bio-hidrogenação de ácidos graxos insaturados C18. A inclusão de 15 a $45 \mathrm{~g} \mathrm{~kg}^{-1}$ de óleo de girassol em dietas à base de cana de açúcar picada melhora a qualidade nutricional da gordura do leite, com aumentos nos teores dos ácidos oleico, vacênico e rumênico, que são benéficos para a saúde humana, e redução nos teores dos ácidos hipercolesterolêmicos láurico, mirístico e palmítico.

Palavras-chave: Ácido linoleico conjugado. Ácido rumênico. Ácido vacênico. Saccharum officinarum.

\section{Introduction}

Sugarcane (Saccharum officinarum L.) is a roughage traditionally used in Brazilian dairy farms during the seasonal period of growth in tropical grasses(Campos, Lopes, Pereira, Machado, \& Tomich, 2017). However, besides the low crude protein (CP) content, sugarcane presents other nutritional limitations that restrict its use as an exclusive forage in the diets of high-producing dairy cows such as a high content of rumen-undegradable neutral detergent fiber (NDF) and a low ruminal digestion rate of the potentially degradable NDF (S. A. Santos et al., 2011; R. C. O. Ribeiro et al., 2015). These fractions induces a marked effect on rumen fill and reduces the dry matter (DM) intake, negatively impacting the productive performance of cows fed sugarcane-based diets (S. A. Santos et al., 2011).

Supplementation with vegetable oils represents an alternative nutritional strategy to augment energy density without increasing the nonfiber carbohydrate (NFC) content in sugarcane-based diets (Rodrigues et al., 2017, 2019). Notably, vegetable oils, including sunflower oil (SO), are rapidly released in the rumen and may have deleterious effects on the resident microbiota and fiber digestion and may affect milk fat content and fatty acid (FA) composition (Rico, Holloway, \& Harvatine, 2015a).

In a companion study performed concomitantly with the present trial using the same treatments, Souza et al. (2019) demonstrated that up to $45 \mathrm{~g} \mathrm{~kg}^{-1}$ SO in a sugarcane-based diet improved the nutritional quality of milk fat as a result of the increased content of oleic (cis-9 C18:1), vaccenic (trans-11 C18:1), and rumenic (cis-9, trans-11 CLA) FAs, all of which are beneficial to human health. In addition to these improvements, there was a decrease in the content of hypercholesterolemic lauric (C12:0), myristic (C14:0), and palmitic (C16:0) FAs. However, SO 
linearly reduced the milk fat content and yield, and there was an increase in trans-10 C18:1 and elaidic acid (trans-9 C18:1), both of which are associated with deleterious effects on cardiovascular health (Vahmani, Meadus, Duff, Rolland, \& Dugan, 2017). This work complements the study of Souza et al. (2019) and presents results contributing to a better understanding of the association between nutrient metabolism and production responses in dairy cows fed sugarcane-based diets containing increasing levels of SO.

The aim of this study was to evaluate the intake and digestion of nutrients, ruminal fermentation and degradation parameters, omasal digesta and milk fatty acid composition, productive performance, and serum metabolites in Holstein $\mathrm{x}$ Gyr cows fed sugarcane-based diets supplemented with sunflower oil.

\section{Materials and Methods}

The study was carried out at Embrapa Dairy Cattle (Coronel Pacheco, MG, Brazil) from July to December 2009. All experimental procedures with animals were conducted according to Embrapa Dairy Cattle guidelines for animal care and use in research. Four multiparous Holstein x Gyr cows
$(500 \pm 39 \mathrm{~kg})$ with $110 \pm 10$ days in milk and producing $15 \pm 5 \mathrm{~kg}$ day $^{-1}$ of milk at the beginning of the study were used. A 4 x 4 Latin square (LS) experimental design with 19-day periods was used, the first 10 days for diet adaptation and the remaining nine days for sampling and data recording.

The experimental treatments were diets based on chopped sugarcane with 0 (control), 15, 30, and $45 \mathrm{~g} \mathrm{~kg}^{-1}$ sunflower oil (SO) provided on a DM basis. The sugarcane variety RB-739735, averaging $18 \pm 4^{\circ}$ brix, was used. Diets were formulated to be isoproteic and isofibrous (Table 1) and to meet the requirements of cows $500 \mathrm{~kg}$ in body weight (BW) producing $17 \mathrm{~kg}^{\text {day }}{ }^{-1}$ of milk with 0.3 $\mathrm{kg}$ day $^{-1}$ of weight gain, in accordance with the recommendations of the National Research Council [NRC] (2001). A more detailed description of the ingredients and chemical composition of the experimental diets was previously described (Souza et al., 2019). Briefly, the diets were formulated at a fixed forage:concentrate ratio of 60:40 (DM basis), and the concentrates were formulated with corn meal, citrus pulp, urea + ammonium sulfate (9:1), mineral and vitamin supplement, and with SO partially replacing the energy from corn meal and citrus pulp.

Table 1

Chemical composition of the experimental diets on a dry matter (DM) basis*

\begin{tabular}{lcccc}
\hline & \multicolumn{4}{c}{ Sunflower oil levels $\left(\mathrm{g} \mathrm{kg}^{-1} \mathrm{DM}\right)$} \\
\cline { 2 - 5 } Item & 0 & 15 & 30 & 45 \\
\hline Chemical composition $\left(\mathrm{g} \mathrm{kg}^{-1} \mathrm{DM}\right)$ & 129 & 128 & 127 & 126 \\
\hline Crude protein & 18 & 32 & 45 & 59 \\
Ether extract & 311 & 312 & 315 & 313 \\
Neutral detergent fiber corrected for ash and protein & 479 & 445 & 411 & 388 \\
Nonfibrous carbohydrate corrected for ash and protein & & & & \\
\hline Fatty acid composition $\left(\mathrm{g} \mathrm{kg}^{-1} \mathrm{DM}\right)$ & 4.21 & 7.93 & 10.66 & 12.14 \\
\hline cis-9 C18:1 (oleic acid) & 7.23 & 17.22 & 26.25 & 31.73 \\
cis-9, cis-12 C18:2 (linoleic acid) & 0.73 & 0.95 & 1.23 & 1.35 \\
cis-9, cis-12, cis-15 C18:3 ( $\alpha$-linolenic acid) & & & & \\
\hline
\end{tabular}

*Source: Adapted from Souza et al. (2019). 
The cows were collectively lodged in a free stall equipped with electronic troughs (American Calan Inc., Northwood, NH, USA) that allowed individual control of feed intake. Feed was supplied ad libitum (10\% of orts) as a TMR once a day ( $08 \mathrm{~h} 00)$ using a mixer/dispenser vehicle (Data Ranger; American Calan Inc.). The sugarcane was chopped daily, and the concentrates with SO were prepared weekly to avoid lipid peroxidation.

Samples of sugarcane and concentrates were collected in each LS period. Samples of individual orts were also collected and pooled per cow. Fecal samples were collected every $26 \mathrm{~h}$ from $08 \mathrm{~h} 00$ on day 11 to day 16 of each LS period, and pooled per cow. All samples were stored $\left(-20^{\circ} \mathrm{C}\right)$, and at the end of the trial, they were thawed, predried $\left(55^{\circ} \mathrm{C}, 72-\right.$ $96 \mathrm{~h}$ ), milled (1 mm) and analyzed in the Laboratory of Food Analysis of Embrapa Dairy Cattle (Juiz de Fora, $\mathrm{MG}$, Brazil) for $\mathrm{DM}$ (at $105^{\circ} \mathrm{C}$ ), $\mathrm{CP}$, ether extract (EE), mineral matter, NDF corrected for ash and protein $\left(\mathrm{NDF}_{\text {ap }}\right)$, NFC corrected for ash and protein $\left(\mathrm{NFC}_{\mathrm{ap}}\right)$ and lignin content, according to Detmann et al. (2012). Samples of chopped sugarcane collected in each LS period and samples of each ingredient of the concentrates, besides the $\mathrm{SO}$, were analyzed for FA composition and the results presented in the companion paper by Souza et al. (2019). Samples of omasal digesta (400 g) were collected using equipment and procedures described by Leão (2002), at $11 \mathrm{~h} 00$ and $23 \mathrm{~h} 00$ on day 12 , at $15 \mathrm{~h} 00$ on day 13 , at $03 \mathrm{~h} 00$ and $19 \mathrm{~h} 00$ on day 14 , and at $07 \mathrm{~h} 00$ on day 15 of each LS period, pooled per cow, stored $\left(-20^{\circ} \mathrm{C}\right)$, lyophilized, ground (1 mm), and analyzed for FA composition as described by Shingfield et al. (2003).

Indigestible neutral detergent fiber, quantified via 264 h of ruminal in situ incubation using F57 filter bags (ANKOM Technology, Macedon, NY, USA), was used as an internal marker to estimate digestibility.

The ruminal parameters were evaluated on the $10^{\text {th }}$ and $11^{\text {th }}$ days of each LS period. Samples of ruminal fluid were collected before (time 0 ) and 2, $4,6,8,10,12,18\left(10^{\text {th }}\right.$ day $)$ and 24 hours $\left(11^{\text {th }}\right.$ day $)$ after the provision of the ration. They were filtered using gauze and the $\mathrm{pH}$ measured using a digital potentiometer. Two $10-\mathrm{mL}$ aliquots were added to flasks with $0.4 \mathrm{~mL}$ of sulfuric acid $(50 \% \mathrm{v} / \mathrm{v}$, subsample 1) or $2 \mathrm{~mL}$ of metaphosphoric acid (25\% $\mathrm{v} / \mathrm{v}$, subsample 2) and frozen. Subsample 1 was analyzed for ammonia $\mathrm{N}$ content $\left(\mathrm{N}-\mathrm{NH}_{3}\right)$ according to the INCT-CA N-007/1 method (Detmann et al., 2012). Subsample 2 was centrifuged (17,000 x $g$ for $10 \mathrm{~min}$ ) and analyzed for the concentration ( $\mathrm{mmol}$ $100 \mathrm{~mL}^{-1}$ ) of volatile fatty acids (VFAs) using a GC model 7820A (Agilent Technologies, Inc., Santa Clara, CA, USA) with a flame ionization detector and Nukol capillary column (30 m x $22 \mathrm{~mm}$ x 0.25 $\mu \mathrm{m})$ connected to free FA (SUPELCO, Bellefonte, PA, USA).

For the study of ruminal degradability (Nocek, $1988)$, a predried $\left(55^{\circ} \mathrm{C}, 72 \mathrm{~h}\right)$ and milled $(5 \mathrm{~mm})$ sample of sugarcane was used, conditioned in nylon bags $(10 \times 20 \mathrm{~cm}, 50 \mu$ porosity, $10-20 \mathrm{mg}$ of sample per $\mathrm{cm}^{2}$ ) and incubated in the rumen of each cow in each LS period. The nylon bags for time 0 were washed and frozen, and the remaining bags were incubated in the rumen and removed 6, 12, 24, 48, 72 and 96 hours later, and frozen. Subsequently, they were washed, predried $\left(55^{\circ} \mathrm{C}, 72 \mathrm{~h}\right)$, and weighed, and the residues were analyzed for DM and NDF contents (Detmann et al., 2012). The ruminal degradability parameters were estimated by adjusting the degradation data as a function of time to a nonlinear model (Tomich \& Sampaio, 2004) using the NLIN procedure of SAS. Curves were generated for each cow in each LS period. The effective degradabilities were calculated (Ørskov $\&$ McDonald, 1979) based on the passage rate of solids in the rumen $\left(\mathrm{kp}, \%\right.$ hour $\left.{ }^{-1}\right)$ estimated by an equation described in NRC (2001): $\mathrm{kp}=3.054+$ $(0.614 * \mathrm{BW}$ _DMI), where BW_DMI is the DM intake ( $\mathrm{kg} 100 \mathrm{~kg}^{-1}$ of body weight).

Cows were milked twice daily (06h00 and 14h00), and their milk yields were recorded from 
the $14^{\text {th }}$ to the $19^{\text {th }}$ days of each LS period. Aliquots of milk from each milking $(2 / 3$ at morning milking + $1 / 3$ at afternoon milking) were collected to compose individual samples $(30 \mathrm{~mL})$, stored in bottles with a bronopol preservative for analysis of protein, fat, lactose and total solids by medium infrared spectrometry (Bentley 2300; Bentley Instruments, Inc., Chaska, MN, USA), and for analysis of milk urea nitrogen (MUN) at the Embrapa Dairy Cattle (Juiz de Fora, MG). Milk samples for FA analyses were collected on the $19^{\text {th }}$ day of each LS period and analyzed using the $\mathrm{GC}$ according to the procedures described by C. G. S. Ribeiro, Lopes, Gama, Rodriguez and Morenz (2018).

The nutritional quality of milk fat was evaluated by the atherogenicity (AI) and thrombogenicity (TI) indices, omega- 6 and omega- 3 FA ratio $(\omega-6 / \omega-3$ FA ratio) and hypo- and hypercholesterolemic FA ratio (h/H FA ratio), calculated according to C. G. S. Ribeiro et al. (2018).

Blood samples were collected on the $17^{\text {th }}$ day of each LS period via coccygeal venipuncture and stored in test tubes (Vacutainer; BectonDickinson, Rutherford, NJ, USA) containing EDTA anticoagulant. The samples were immediately centrifuged at 3,000 $\mathrm{x} \mathrm{g}$ for $15 \mathrm{~min}$, and plasma $(2 \mathrm{~mL})$ was stored in tubes $\left(-20^{\circ} \mathrm{C}\right)$ until analysis. The serum contents of nonesterified FA (NEFA), glucose, cholesterol, triglycerides and urea nitrogen were analyzed using commercial kits as described by Rodrigues et al. (2017).

The results were analyzed using mixed models using the MIXED procedure of SAS. The ruminal fermentation parameters were analyzed as repeated measures in time, with the following considered to be fixed effects: treatment (level of SO in the diet), sampling time and the interaction between these factors; and the following were considered random effects: cow, LS period and the interaction cow*LS period*treatment. Ten matrices of covariance were evaluated based on the Akaike information criterion. The other variables were analyzed considering treatment as a fixed effect and cow and LS period as random effects. The linear and quadratic effects of the treatments were analyzed using orthogonal contrasts. The results are reported as least squares means, and significant differences were declared at $\mathrm{P}<0.05$. Regression equations between specific variables were adjusted using the REG procedure, and Pearson correlations were calculated using the CORR procedure of SAS.

\section{Results}

There was no effect $(\mathrm{P}>0.05)$ of SO on the intake

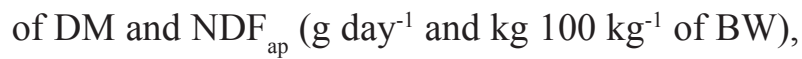
$\mathrm{CP}, \mathrm{NFC}_{\text {ap }}$ and total digestible nutrients (TDN), but there was a linear increase $(\mathrm{P}<0.0001)$ in the intakes of EE and $\alpha$-linolenic acid (Table 2). SO promoted quadratic effects $(\mathrm{P}<0.05)$ on the palmitic, stearic (C18:0), oleic and linoleic acid intakes (Table 2); maximum values of 79, 28, 177 and $468 \mathrm{~g}$ day $^{-1}$ were estimated when $35.9,43.2,42.5$ and $51.2 \mathrm{~g} \mathrm{~kg}^{-1} \mathrm{SO}$ was added to the diet, respectively. There was no effect $(\mathrm{P}>0.05)$ of $\mathrm{SO}$ on the apparent digestibility of $\mathrm{DM}, \mathrm{CP}, \mathrm{NDF}_{\text {ap }}$ and $\mathrm{NFC}_{\text {ap }}$, but $\mathrm{SO}$ promoted a linear increase in the apparent digestibility of $\mathrm{EE}$ $(\mathrm{P}=0.0057)$ and on TDN $(\mathrm{P}=0.0032)$ (Table 2$)$.

There was no effect $(\mathrm{P}>0.05)$ of $\mathrm{SO}$ on the rate passage of solids in the rumen and on the ruminal degradability parameters for DM and NDF (Table 3). The treatment*sampling time interaction was not significant $(\mathrm{P}>0.05)$ for any of the ruminal parameters (Table 4). No effect was observed $(\mathrm{P}>0.05)$ of the treatments on rumen $\mathrm{pH}$, acetate:propionate ratio, and on rumen contents of $\mathrm{N}_{-} \mathrm{NH}_{3}$, acetate, propionate and total VFAs, but $\mathrm{SO}$ promoted a linear reduction $(\mathrm{P}=0.0254)$ in the rumen content of butyrate (Table 4). The sampling time promoted a quadratic effect on rumen $\mathrm{pH}$ and total VFA content. The minimum rumen $\mathrm{pH}$ value was 5.8, and the maximum value of rumen total VFA content was $72.6 \mathrm{mmol} 100 \mathrm{~mL}^{-1}$, estimated to occur at $11.3 \mathrm{~h}$ and $11.9 \mathrm{~h}$ after the provision of the ration, respectively (Figure 1). 
Table 2

Intake and apparent digestibility of nutrients in Holstein $x$ Gyr cows fed sugarcane-based diets containing increasing levels of sunflower oil (SO)

\begin{tabular}{|c|c|c|c|c|c|c|c|}
\hline \multirow{2}{*}{ Item } & \multicolumn{4}{|c|}{ SO levels ( $\left.\mathrm{g} \mathrm{kg}^{-1} \mathrm{DM}\right)$} & \multirow[b]{2}{*}{ SEM } & \multicolumn{2}{|c|}{ P-value } \\
\hline & 0 & 15 & 30 & 45 & & Linear & Quadratic \\
\hline \multicolumn{8}{|c|}{ Nutrient intake $\left(\mathrm{kg} \mathrm{day}^{-1}\right)$} \\
\hline Dry matter (DM) & 14.6 & 15.5 & 16.1 & 14.4 & 1.2797 & 0.9672 & 0.1131 \\
\hline Crude protein (CP) & 1.85 & 1.96 & 2.00 & 1.80 & 0.1419 & 0.7664 & 0.1501 \\
\hline Ether extract (EE) & 0.258 & 0.508 & 0.733 & 0.878 & 0.0492 & $<0.0001$ & 0.2357 \\
\hline $\mathrm{NDF}_{\mathrm{ap}}^{\mathrm{a}}$ & 5.00 & 5.42 & 5.79 & 5.10 & 0.5114 & 0.6213 & 0.1041 \\
\hline $\mathrm{NFC}_{\mathrm{ap}} \mathrm{b}^{\mathrm{b}}$ & 7.20 & 7.23 & 7.12 & 6.26 & 0.6426 & 0.0599 & 0.1643 \\
\hline $\mathrm{TDN}^{\mathrm{c}}$ & 10.8 & 11.6 & 12.1 & 11.4 & 1.0905 & 0.2828 & 0.1480 \\
\hline \multicolumn{8}{|c|}{ Fatty acid intake $\left(\mathrm{g} \mathrm{day}^{-1}\right)$} \\
\hline Palmitic acid & 42.9 & 63.9 & 79.8 & 75.4 & 5.7661 & 0.0004 & 0.0125 \\
\hline Stearic acid & 8.2 & 18.0 & 27.3 & 27.4 & 1.9937 & $<0.0001$ & 0.0107 \\
\hline Oleic acid & 61.3 & 123.0 & 171.4 & 174.8 & 12.8590 & $<0.0001$ & 0.0138 \\
\hline Linoleic acid & 105.2 & 267.0 & 422.2 & 457.2 & 32.9181 & $<0.0001$ & 0.0300 \\
\hline$\alpha$-linolenic acid & 10.6 & 14.6 & 19.8 & 19.4 & 1.4927 & $<0.0001$ & 0.0512 \\
\hline \multicolumn{8}{|c|}{ Nutrient intake (kg $100 \mathrm{~kg}^{-1}$ of body weight) } \\
\hline $\mathrm{DM}$ & 3.03 & 3.23 & 3.42 & 3.04 & 0.2382 & 0.7827 & 0.1247 \\
\hline $\mathrm{NDF}_{\mathrm{ap}}{ }^{\mathrm{a}}$ & 1.04 & 1.13 & 1.20 & 1.08 & 0.1000 & 0.5418 & 0.1334 \\
\hline \multicolumn{8}{|c|}{ Apparent digestibility (\%) } \\
\hline $\mathrm{DM}$ & 71.3 & 70.3 & 69.4 & 71.4 & 2.3737 & 0.8939 & 0.1119 \\
\hline $\mathrm{CP}$ & 69.1 & 68.1 & 69.7 & 70.6 & 2.8639 & 0.3616 & 0.5409 \\
\hline $\mathrm{EE}$ & 86.8 & 95.3 & 93.7 & 97.2 & 1.6600 & 0.0057 & 0.1691 \\
\hline $\mathrm{NDF}_{\mathrm{ap}} \mathrm{a}^{\mathrm{a}}$ & 42.5 & 42.9 & 42.9 & 46.7 & 4.5954 & 0.0745 & 0.2688 \\
\hline $\mathrm{NFC}_{\mathrm{ap}}^{\mathrm{ap}}$ & 95.4 & 94.7 & 93.6 & 93.9 & 0.9904 & 0.0668 & 0.4397 \\
\hline $\mathrm{TDN}^{\mathrm{ap}}$ & 73.5 & 74.9 & 75.2 & 79.6 & 2.6619 & 0.0032 & 0.1262 \\
\hline
\end{tabular}

${ }^{\mathrm{a}} \mathrm{NDF}_{\mathrm{ap}}=$ neutral detergent fiber corrected for ash and protein; ${ }^{\mathrm{b}} \mathrm{NFC}_{\mathrm{ap}}=$ nonfibrous carbohydrate corrected for ash and protein;

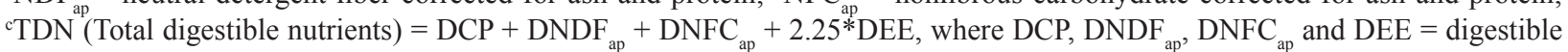
$\mathrm{CP}, \mathrm{NDF}_{\mathrm{ap}}, \mathrm{NFC}_{\text {ap }}$ and EE, respectively (Weiss, 1999).

\section{Table 3}

Rate passage of solids in the rumen and the dry matter (DM) and neutral detergent fiber (NDF) degradability parameters of chopped sugarcane in Holstein $x$ Gyr cows fed sugarcane-based diets containing increasing levels of sunflower oil (SO)

\begin{tabular}{|c|c|c|c|c|c|c|c|}
\hline \multirow{2}{*}{ Item } & \multicolumn{4}{|c|}{ SO levels ( $\left.\mathrm{g} \mathrm{kg}^{-1} \mathrm{DM}\right)$} & \multirow[b]{2}{*}{ SEM } & \multicolumn{2}{|c|}{ P-value } \\
\hline & 0 & 15 & 30 & 45 & & Linear & Quadratic \\
\hline Rate passage of solids in the rumen ${ }^{\mathrm{a}}$ & 4.91 & 5.04 & 5.15 & 4.92 & 0.1463 & 0.7827 & 0.1247 \\
\hline \multicolumn{8}{|l|}{ Ruminal DM degradability } \\
\hline Potential degradability (\%) & 67.9 & 68.5 & 66.5 & 68.7 & 0.8695 & 0.9400 & 0.3639 \\
\hline Degradation rate $\left(\%\right.$ hour $\left.^{-1}\right)$ & 2.26 & 2.19 & 2.43 & 2.11 & 0.4105 & 0.7779 & 0.4813 \\
\hline Effective degradability $(\%)^{\mathrm{b}}$ & 25.1 & 25.2 & 25.4 & 24.4 & 2.3445 & 0.6119 & 0.5561 \\
\hline \multicolumn{8}{|l|}{ Ruminal NDF degradability } \\
\hline Potential degradability (\%) & 48.6 & 48.1 & 46.8 & 51.6 & 2.1597 & 0.3242 & 0.1443 \\
\hline Degradation rate $\left(\%\right.$ hour $\left.^{-1}\right)$ & 2.40 & 2.35 & 2.55 & 2.29 & 0.4102 & 0.8587 & 0.5536 \\
\hline Effective degradability $(\%)^{\mathrm{b}}$ & 15.3 & 15.1 & 15.0 & 15.6 & 1.6252 & 0.6645 & 0.3473 \\
\hline
\end{tabular}

${ }^{a}$ Estimated by the following equation (NRC, 2001): $3.054+\left(0.614 * B W \_D M I\right)$. Where BW_DMI is the DM intake expressed in $\mathrm{kg} 100 \mathrm{~kg}^{-1}$ of body weight; ${ }^{\mathrm{b}} \mathrm{Calculated}$ considering the passage rate of solids in the rumen estimated by the NRC (2001) equation for wet forage. 
Table 4

Ruminal fermentation parameters in Holstein x Gyr cows fed sugarcane-based diets containing increasing levels of sunflower oil (SO)

\begin{tabular}{|c|c|c|c|c|c|c|c|c|}
\hline \multirow{2}{*}{ Item } & \multicolumn{4}{|c|}{ SO levels $\left(\mathrm{g} \mathrm{kg}^{-1} \mathrm{DM}\right)$} & \multirow[b]{2}{*}{ SEM } & \multicolumn{3}{|c|}{ P-value } \\
\hline & 0 & 15 & 30 & 45 & & Linear & Quadratic & Trat*Time $^{a}$ \\
\hline$\overline{\mathrm{pH}}$ & 6.15 & 6.07 & 6.20 & 6.15 & 0.1675 & 0.6698 & 0.8501 & 0.7894 \\
\hline Ammonia $\mathrm{N}\left(\mathrm{mg} \mathrm{dL}^{-1}\right)$ & 14.99 & 12.03 & 13.46 & 13.22 & 1.9371 & 0.5883 & 0.5966 & 0.9661 \\
\hline Acetate (A) & 42.41 & 37.07 & 40.36 & 39.75 & 3.3925 & 0.5903 & 0.2367 & 0.5960 \\
\hline Propionate (P) & 15.59 & 13.41 & 15.29 & 16.09 & 1.3019 & 0.4758 & 0.1664 & 0.9314 \\
\hline Butyrate & 10.20 & 9.04 & 8.42 & 9.85 & 0.9664 & 0.4113 & 0.0254 & 0.9400 \\
\hline $\mathrm{VFA}^{\mathrm{b}}$ & 68.21 & 59.52 & 64.07 & 65.68 & 5.0670 & 0.8425 & 0.1456 & 0.8368 \\
\hline A: $P$ ratio & 2.91 & 2.91 & 2.80 & 2.70 & 0.1799 & 0.3384 & 0.7278 & 0.7326 \\
\hline
\end{tabular}

Interaction between treatment $\left(\mathrm{g} \mathrm{kg}^{-1}\right.$ sunflower oil in the diet) and sampling time; ${ }^{\mathrm{b}} \mathrm{VFA}$ (volatile fatty acids) $=\Sigma$ ruminal concentrations $\left(\mathrm{mmol} 100 \mathrm{~mL}^{-1}\right)$ of acetate + propionate + butyrate.
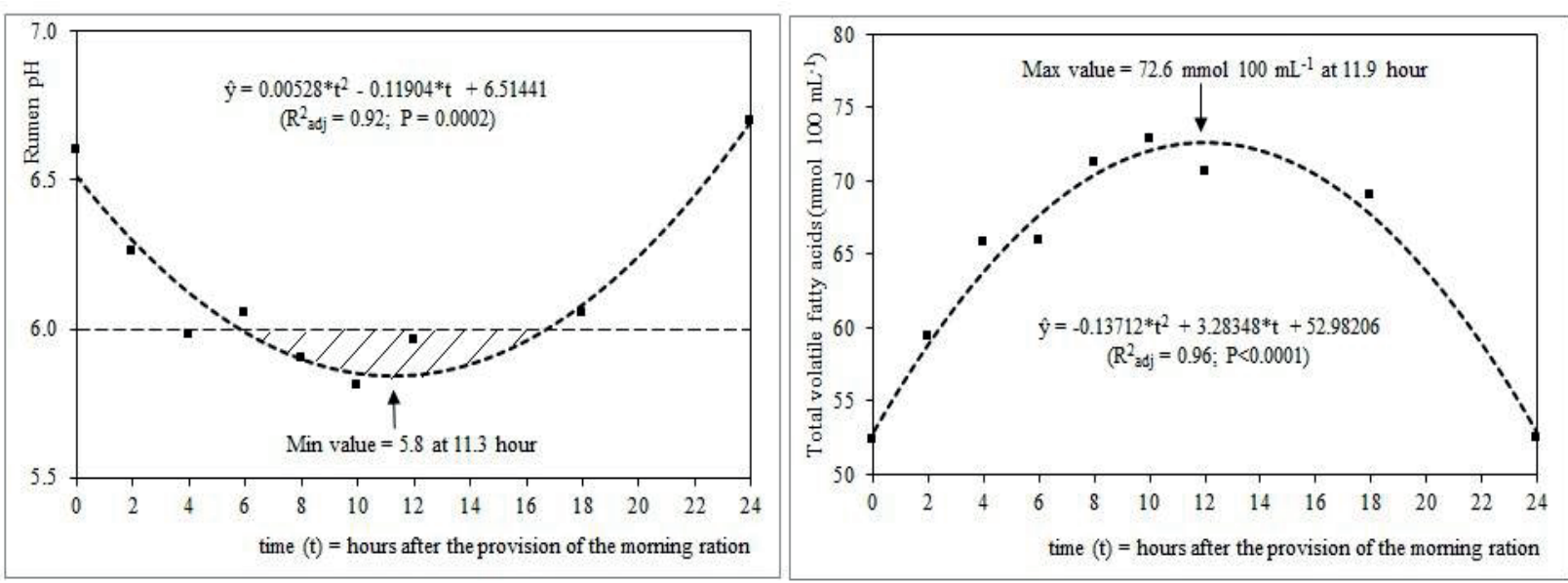

Figure 1. Effect of sampling time ( $\mathrm{t}$, hour) on rumen fermentation parameters in Holstein $\mathrm{x}$ Gyr cows fed sugarcanebased diets containing $0,15,30$, and $45 \mathrm{~g} \mathrm{~kg}^{-1}$ sunflower oil on a dry matter basis.

SO promoted linear decreases in milk fat $(\mathrm{P}=0.0026)$ and total solids contents $(\mathrm{P}=0.0046)$ and a linear increase in milk protein content $(\mathrm{P}=0.0242)$. However, no effect $(\mathrm{P}>0.05)$ on MUN and milk lactose content was observed. The milk yield, fatcorrected milk yield, and milk protein, lactose and total solids yields were not influenced $(\mathrm{P}>0.05)$ by $\mathrm{SO}$, but there was a linear reduction $(\mathrm{P}=0.0328)$ in milk fat yield (Table 5). SO promoted a linear decrease $(\mathrm{P}=0.0025)$ in the apparent transfer into milk of ingested $\alpha$-linolenic acid and a quadratic effect $(\mathrm{P}<0.05)$ on the apparent transfer of ingested oleic and linoleic acids into milk (Table 5) with maximum values of 0.408 and 0.183 estimated for 36.8 and $35.4 \mathrm{~g} \mathrm{~kg}^{-1} \mathrm{SO}$ in the ration, respectively.
There was no effect $(\mathrm{P}>0.05)$ of $\mathrm{SO}$ on the serum concentrations of glucose, NEFA, triglycerides and urea nitrogen, but there was a quadratic effect $(\mathrm{P}=0.0247)$ on serum cholesterol content (Table 6) with a maximum value $\left(175.7 \mathrm{mg} \mathrm{dL}^{-1}\right)$ estimated when $32.8 \mathrm{~g} \mathrm{~kg}^{-1} \mathrm{SO}$ was added to the diet.

SO promoted linear reductions $(\mathrm{P}<0.05)$ in the omasal digesta contents of palmitic and $\alpha$-linolenic acids, linear increases $(\mathrm{P}<0.05)$ in trans-10 $\mathrm{C} 18: 1$ and elaidic acid contents, and quadratic effects $(\mathrm{P}<0.05)$ on de novo-synthesized FAs $\mathrm{C} 4: 0$ to $\mathrm{C} 16: 0$ and on the vaccenic and rumenic acid contents (Table 7). The minimum omasal digesta content

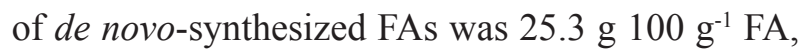


estimated to occur at $29.8 \mathrm{~g} \mathrm{~kg}^{-1} \mathrm{SO}$ in the ration, while the maximum omasal digesta contents of vaccenic and rumenic acid were 9.03 and $1.45 \mathrm{~g} 100$ $\mathrm{g}^{-1} \mathrm{FA}$, estimated to occur at 31.8 and $19.8 \mathrm{~g} \mathrm{~kg}^{-1}$ $\mathrm{SO}$ in the ration, respectively. SO promoted linear reductions $(\mathrm{P}<0.01)$ in the milk fat contents of the major odd- and branched-chain FAs (OBCFAs), and lauric, myristic and palmitic acids, and linear increases $(\mathrm{P}<0.05)$ in stearic, oleic, elaidic, trans -10
C18:1, trans-10, cis-12 CLA, trans-9, cis-11 CLA, vaccenic and rumenic FA contents (Tables 8 and 9). SO did not alter the milk fat linoleic and $\alpha$-linolenic acid contents (Table 9). SO promoted a linear reduction $(\mathrm{P}=0.0061)$ in $\mathrm{SCD}$ activity only for rumenic/vaccenic FAs (data not shown). SO promoted linear reductions in $\mathrm{AI}$ and $\mathrm{TI}(\mathrm{P}<0.01)$ and linear increases $(\mathrm{P}=0.001)$ in the $\mathrm{h} / \mathrm{H}$ and $\omega-6: \omega-3(\mathrm{P}=0.003)$ FA ratios (data not shown).

\section{Table 5}

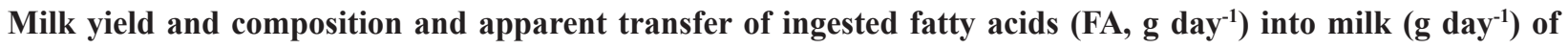
Holstein x Gyr cows fed sugarcane-based diets containing increasing levels of sunflower oil (SO)

\begin{tabular}{|c|c|c|c|c|c|c|c|}
\hline \multirow{2}{*}{ Item } & \multicolumn{4}{|c|}{ SO levels ( $\left.\mathrm{g} \mathrm{kg}^{-1} \mathrm{DM}\right)$} & \multirow[b]{2}{*}{ SEM } & \multicolumn{2}{|c|}{ P-value } \\
\hline & 0 & 15 & 30 & 45 & & Linear & Quadratic \\
\hline \multicolumn{8}{|l|}{ Yield } \\
\hline Milk (kg day $\left.{ }^{-1}\right)$ & 15.1 & 15.6 & 16.1 & 15.1 & 1.1168 & 0.8650 & 0.4279 \\
\hline FCM $\left(\mathrm{kg} \mathrm{day}{ }^{-1}\right)^{\mathrm{a}}$ & 14.4 & 13.8 & 12.8 & 12.0 & 1.0201 & 0.1123 & 0.9246 \\
\hline Fat $\left(\mathrm{g} \mathrm{day}^{-1}\right)$ & 556.2 & 503.2 & 424.6 & 397.0 & 46.7803 & 0.0328 & 0.7879 \\
\hline Protein $\left(\mathrm{g} \mathrm{day}^{-1}\right)$ & 490.0 & 498.3 & 526.1 & 521.6 & 45.0530 & 0.2872 & 0.7934 \\
\hline Lactose $\left(\mathrm{g} \mathrm{day}^{-1}\right)$ & 653.0 & 687.6 & 690.8 & 646.8 & 48.9985 & 0.9298 & 0.3367 \\
\hline Total solids $\left(\mathrm{g} \mathrm{day}^{-1}\right)$ & $1,834.0$ & $1,827.2$ & $1,778.1$ & $1,693,6$ & 126.690 & 0.3747 & 0.7352 \\
\hline \multicolumn{8}{|l|}{ Composition (\%) } \\
\hline Fat & 3.69 & 3.25 & 2.66 & 2.65 & 0.2400 & 0.0026 & 0.2555 \\
\hline Protein & 3.25 & 3.20 & 3.29 & 3.44 & 0.1683 & 0.0242 & 0.0929 \\
\hline Lactose & 4.34 & 4.43 & 4.31 & 4.28 & 0.0743 & 0.0717 & 0.1085 \\
\hline Total solids & 12.16 & 11.76 & 11.10 & 11.22 & 0.2540 & 0.0046 & 0.1999 \\
\hline Milk urea $\mathrm{N}\left(\mathrm{mg} \mathrm{dL}^{-1}\right)$ & 12.2 & 13.1 & 10.7 & 11.1 & 1.5074 & 0.3333 & 0.8329 \\
\hline \multicolumn{8}{|c|}{ Apparent transfer of ingested fatty acids $\left(\mathrm{FA}, \mathrm{g}\right.$ day $\left.^{-1}\right)$ into milk $\left(\mathrm{g} \mathrm{day}^{-1}\right)$} \\
\hline Oleic acid & 1.399 & 0.709 & 0.483 & 0.443 & 0.1047 & 0.0003 & 0.0207 \\
\hline Linoleic acid & 0.102 & 0.035 & 0.025 & 0.018 & 0.0066 & $<0.0001$ & 0.0035 \\
\hline$\alpha$-Linolenic acid & 0.087 & 0.043 & 0.032 & 0.020 & 0.0098 & 0.0025 & 0.1487 \\
\hline
\end{tabular}

${ }^{\mathrm{a}}$ Fat-corrected milk $(\mathrm{NRC}, 2001)=(0.4 *$ MilkProd $)+15 *($ MilkFat*/100)*MilkProd.

Table 6

Serum metabolites in cows fed sugarcane-based diets containing increasing levels of sunflower oil (SO)

\begin{tabular}{|c|c|c|c|c|c|c|c|}
\hline \multirow{2}{*}{ Metabolite } & \multicolumn{4}{|c|}{ SO levels ( $\left.\mathrm{g} \mathrm{kg}^{-1} \mathrm{DM}\right)$} & \multirow[b]{2}{*}{ SEM } & \multicolumn{2}{|c|}{ P-value } \\
\hline & 0 & 15 & 30 & 45 & & Linear & Quadratic \\
\hline Glucose (mg dL $\left.{ }^{-1}\right)$ & 52.5 & 52.9 & 58.5 & 56.3 & 2.4578 & 0.0569 & 0.4891 \\
\hline Nonesterified fatty acids $\left(\mathrm{mmol} \mathrm{L}{ }^{-1}\right)$ & 0.168 & 0.223 & 0.240 & 0.165 & 0.0705 & 0.9598 & 0.1811 \\
\hline Cholesterol (mg dL $\left.{ }^{-1}\right)$ & 88.7 & 137.3 & 186.7 & 159.3 & 15.7748 & 0.0038 & 0.0247 \\
\hline Triglycerides $\left(\mathrm{mg} \mathrm{dL}^{-1}\right)$ & 3.27 & 3.43 & 3.87 & 4.45 & 0.8382 & 0.3263 & 0.8074 \\
\hline Urea nitrogen $\left(\mathrm{mg} \mathrm{dL}^{-1}\right)$ & 10.8 & 14.1 & 11.8 & 10.5 & 3.0080 & 0.3844 & 0.1224 \\
\hline
\end{tabular}


Table 7

Selected fatty acids (FA) in omasal digesta of Holstein $x$ Gyr cows fed sugarcane-based diets containing increasing levels of sunflower oil (SO)

\begin{tabular}{|c|c|c|c|c|c|c|c|}
\hline \multirow{2}{*}{ Fatty acid (g $\left.100 \mathrm{~g}^{-1} \mathrm{FA}\right)$} & \multicolumn{4}{|c|}{ SO levels $\left(\mathrm{g} \mathrm{kg}^{-1} \mathrm{DM}\right)$} & \multirow[b]{2}{*}{ SEM } & \multicolumn{2}{|c|}{ P-value } \\
\hline & 0 & 15 & 30 & 45 & & Linear & Quadratic \\
\hline$\overline{\Sigma 4 \leq \mathrm{C} \leq 10}$ & 4.15 & 2.54 & 2.60 & 3.09 & 0.4024 & 0.1234 & 0.0358 \\
\hline $\mathrm{C} 12: 0$ & 8.54 & 7.13 & 5.57 & 6.65 & 0.7985 & 0.0894 & 0.1703 \\
\hline $\mathrm{C} 14: 0$ & 5.23 & 2.82 & 3.25 & 3.18 & 0.6262 & 0.0790 & 0.1028 \\
\hline $\mathrm{C} 16: 0$ & 19.53 & 14.62 & 15.00 & 15.10 & 1.2948 & 0.0489 & 0.0765 \\
\hline$\Sigma 4 \leq \mathrm{C} \leq 16$ & 37.45 & 27.11 & 26.40 & 28.01 & 2.5504 & 0.0366 & 0.0487 \\
\hline $\mathrm{C} 18: 0$ & 23.94 & 31.64 & 29.71 & 28.61 & 2.6787 & 0.3398 & 0.1419 \\
\hline iso $\mathrm{C} 15: 0$ & 0.68 & 0.55 & 0.50 & 0.54 & 0.0606 & 0.1251 & 0.2042 \\
\hline anteiso $\mathrm{C} 15: 0$ & 0.99 & 0.69 & 0.72 & 0.72 & 0.0864 & 0.0886 & 0.1364 \\
\hline $\mathrm{C} 15: 0$ & 0.56 & 0.74 & 0.52 & 0.59 & 0.0630 & 0.7223 & 0.3968 \\
\hline $\mathrm{C} 17: 0$ & 0.52 & 0.40 & 0.34 & 0.40 & 0.0574 & 0.1450 & 0.1583 \\
\hline cis-9 C18:1 & 11.66 & 10.37 & 9.62 & 8.33 & 1.5235 & 0.1656 & 0.9981 \\
\hline trans-9 C18:1 & 0.29 & 0.57 & 0.62 & 0.63 & 0.0811 & 0.0185 & 0.1179 \\
\hline trans-10 C18:1 & 0.61 & 3.48 & 4.71 & 7.02 & 1.9306 & 0.0124 & 0.3347 \\
\hline trans-11 C18:1 & 2.62 & 7.18 & 9.08 & 7.90 & 1.9613 & 0.0273 & 0.0198 \\
\hline cis-9, trans-11 CLA & 1.17 & 1.59 & 1.24 & 1.14 & 0.1731 & 0.3515 & 0.0433 \\
\hline trans -10 , cis-12 CLA & 0.13 & 0.32 & 0.22 & 0.33 & 0.0763 & 0.0888 & 0.5175 \\
\hline cis-9, cis-12 C18:2 ( $\omega-6)$ & 2.49 & 2.34 & 2.24 & 1.91 & 0.4168 & 0.3067 & 0.8111 \\
\hline$c i s-9, c i s-12, c i s-15 \mathrm{C} 18: 3(\omega-3)$ & 0.29 & 0.18 & 0.19 & 0.14 & 0.0333 & 0.0036 & 0.2191 \\
\hline \multicolumn{8}{|l|}{ Ratios between FAs } \\
\hline$\overline{\mathrm{C} 18: 0 / \text { trans-11 C18:1 }}$ & 9.24 & 4.44 & 3.43 & 6.25 & 1.2830 & 0.1271 & 0.0234 \\
\hline C18:0/trans-10 C18:1 & 39.20 & 20.51 & 10.89 & 13.90 & 7.2149 & 0.0217 & 0.3242 \\
\hline trans-11 C18:1/trans-10 C18:1 & 4.27 & 4.70 & 3.74 & 2.18 & 1.5320 & 0.0616 & 0.4970 \\
\hline
\end{tabular}

Table 8

Fatty acid (FA) composition in milk fat from Holstein x Gyr cows fed sugarcane-based diets containing increasing levels of sunflower oil (SO)

\begin{tabular}{|c|c|c|c|c|c|c|c|}
\hline \multirow{2}{*}{ Fatty acid (g $\left.100 \mathrm{~g}^{-1} \mathrm{FA}\right)$} & \multicolumn{4}{|c|}{ SO levels $\left(\mathrm{g} \mathrm{kg}^{-1} \mathrm{DM}\right)$} & \multirow[b]{2}{*}{ SEM } & \multicolumn{2}{|c|}{ P-value } \\
\hline & 0 & 15 & 30 & 45 & & Linear & Quadratic \\
\hline \multicolumn{8}{|l|}{ Linear even-chain saturated FA } \\
\hline$\Sigma 4 \leq \mathrm{C} \leq 10$ & 9.37 & 8.22 & 6.98 & 4.35 & 0.9097 & 0.0061 & 0.4328 \\
\hline $\mathrm{C} 12: 0$ & 2.93 & 2.44 & 1.63 & 1.13 & 0.2844 & 0.0004 & 0.9806 \\
\hline $\mathrm{C} 14: 0$ & 11.47 & 10.11 & 7.85 & 6.07 & 0.7700 & 0.0001 & 0.6652 \\
\hline $\mathrm{C} 16: 0$ & 35.35 & 29.87 & 21.69 & 20.14 & 2.4593 & 0.0021 & 0.4339 \\
\hline$\Sigma 12 \leq \mathrm{C} \leq 16$ & 49.75 & 42.42 & 31.17 & 27.33 & 2.8065 & 0.0006 & 0.5384 \\
\hline$\sum 4 \leq \mathrm{C} \leq 16$ & 59.11 & 50.64 & 38.15 & 31.67 & 3.0754 & 0.0003 & 0.7367 \\
\hline C18:0 & 10.06 & 12.59 & 14.51 & 14.48 & 1.1600 & 0.0032 & 0.1229 \\
\hline $\mathrm{C} 18: 0+\mathrm{C} 20: 0+\mathrm{C} 22: 0+\mathrm{C} 24: 0$ & 10.31 & 12.87 & 14.78 & 14.77 & 1.1827 & 0.0032 & 0.1244 \\
\hline \multicolumn{8}{|c|}{ Odd- and branched-chain FA (OBCFA) } \\
\hline iso $\mathrm{C} 15: 0$ & 0.30 & 0.21 & 0.19 & 0.12 & 0.0200 & $<0.0001$ & 0.4107 \\
\hline anteiso $\mathrm{C} 15: 0$ & 0.60 & 0.45 & 0.52 & 0.35 & 0.0310 & 0.0031 & 0.7578 \\
\hline $\mathrm{C} 15: 0$ & 1.42 & 1.20 & 1.09 & 0.93 & 0.0565 & 0.0003 & 0.5439 \\
\hline C17:0 & 0.59 & 0.55 & 0.56 & 0.48 & 0.0392 & 0.0081 & 0.3650 \\
\hline
\end{tabular}




\begin{tabular}{lccccccc} 
continuation & & & & & & & \\
cis-9 C17:1 & 0.23 & 0.19 & 0.15 & 0.13 & 0.0180 & 0.0051 & 0.6260 \\
乏 OBCFA & 3.51 & 2.88 & 2.74 & 2.20 & 0.1229 & 0.0003 & 0.7095 \\
\hline cis-C18:1 FA & & & & & & & \\
\hline cis-9 C18:1 & 16.39 & 18.81 & 21.05 & 20.32 & 1.4597 & 0.0074 & 0.0937 \\
cis-11 C18:1 & 1.11 & 1.16 & 1.28 & 1.36 & 0.1465 & 0.1321 & 0.8839 \\
cis-12 C18:1 & 0.27 & 0.52 & 0.67 & 0.82 & 0.0942 & 0.0052 & 0.6410 \\
cis-13 C18:1 & 0.051 & 0.072 & 0.235 & 0.224 & 0.1011 & 0.0921 & 0.8645 \\
\hline
\end{tabular}

Table 9

Fatty acid (FA) composition in milk fat from Holstein x Gyr cows fed sugarcane-based diets containing increasing levels of sunflower oil (SO)

\begin{tabular}{|c|c|c|c|c|c|c|c|}
\hline \multirow{2}{*}{ Fatty acid (g $\left.100 \mathrm{~g}^{-1} \mathrm{FA}\right)$} & \multicolumn{4}{|c|}{ SO levels ( $\left.\mathrm{g} \mathrm{kg}^{-1} \mathrm{DM}\right)$} & \multirow[b]{2}{*}{ SEM } & \multicolumn{2}{|c|}{$\mathrm{P}$-value } \\
\hline & 0 & 15 & 30 & 45 & & Linear & Quadratic \\
\hline \multicolumn{8}{|l|}{ trans-C18:1 FA } \\
\hline trans-4 C18:1 & 0.014 & 0.036 & 0.041 & 0.059 & 0.0058 & 0.0005 & 0.6718 \\
\hline trans-5 C18:1 & 0.017 & 0.035 & 0.060 & 0.081 & 0.0130 & 0.0011 & 0.8896 \\
\hline trans-6-8 C18:1 & 0.11 & 0.34 & 0.44 & 0.76 & 0.0815 & 0.0006 & 0.5400 \\
\hline trans-9 C18:1 & 0.18 & 0.36 & 0.41 & 0.75 & 0.0626 & 0.0002 & 0.2617 \\
\hline trans-10 C18:1 & 0.35 & 1.17 & 1.06 & 3.78 & 0.8310 & 0.0076 & 0.3833 \\
\hline trans-11 C18:1 & 1.11 & 2.98 & 6.26 & 9.39 & 1.3960 & 0.0013 & 0.5248 \\
\hline trans-12 C18:1 & 0.18 & 0.49 & 0.80 & 1.38 & 0.1280 & 0.0004 & 0.3341 \\
\hline trans-13-14 C18:1 & 0.27 & 0.59 & 0.78 & 1.29 & 0.0791 & $<0.0001$ & 0.2050 \\
\hline trans-16 C18:1 & 0.15 & 0.21 & 0.60 & 0.63 & 0.1521 & 0.0089 & 0.9226 \\
\hline$\underline{\Sigma}$ trans $-\mathrm{C} 18: 1$ & 2.37 & 6.21 & 10.44 & 18.12 & 1.3716 & 0.0001 & 0.2015 \\
\hline \multicolumn{8}{|c|}{ Conjugated (CLA) and nonconjugated isomers of linoleic acid } \\
\hline cis-9, trans-12 C18:2 & 0.07 & 0.14 & 0.16 & 0.17 & 0.0267 & 0.0107 & 0.1420 \\
\hline cis-9, trans-11 CLA & 0.52 & 1.15 & 2.41 & 2.67 & 0.4643 & 0.0080 & 0.6933 \\
\hline trans-9, cis-11 CLA & 0.034 & 0.054 & 0.096 & 0.108 & 0.0132 & 0.0018 & 0.7250 \\
\hline trans -10 , cis-12 CLA & 0.023 & 0.053 & 0.061 & 0.123 & 0.0216 & 0.0015 & 0.2777 \\
\hline \multicolumn{8}{|l|}{ Long-chain polyunsaturated FA } \\
\hline 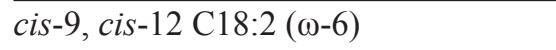 & 2.04 & 2.01 & 2.70 & 2.24 & 0.2123 & 0.2134 & 0.3258 \\
\hline cis-6, cis-9, cis-12 C18:3 ( $\omega-6)$ & 0.101 & 0.092 & 0.091 & 0.058 & 0.0122 & 0.0101 & 0.1744 \\
\hline$c i s-9, c i s-12, c i s-15 \mathrm{C} 18: 3(\omega-3)$ & 0.17 & 0.13 & 0.16 & 0.10 & 0.0172 & 0.0536 & 0.5907 \\
\hline cis-11, cis-14 C20:2 ( $\omega-6)$ & 0.025 & 0.028 & 0.026 & 0.024 & 0.0087 & 0.8456 & 0.7118 \\
\hline$c i s-8, c i s-11, c i s-14$ C20:3 ( $\omega-6)$ & 0.074 & 0.056 & 0.061 & 0.039 & 0.0088 & 0.0269 & 0.8139 \\
\hline cis- 5, cis-8, cis-11, cis-14 C20:4 ( $\omega-6)$ & 0.134 & 0.086 & 0.095 & 0.054 & 0.0121 & 0.0054 & 0.7671 \\
\hline
\end{tabular}

\section{Discussion}

The absence of an effect $(\mathrm{P}>0.05)$ of $\mathrm{SO}$ on $\mathrm{DM}$ and $\mathrm{NDF}_{\text {ap }}$ intake and apparent digestibility (Table 2) corroborates the results of the productive performance trial, presented in our companion paper (Souza et al., 2019). Additionally, the dietary EE content (Table 1) did not exceed 60-70 $\mathrm{g} \mathrm{kg}^{-1} \mathrm{DM}$ (NRC, 2001), and we employed a strategy of mixing the SO with the concentrate (Lopes et al., 2019). This technique probably avoided the deposition of a layer of oil on the forage particles, which could negatively impair both the adhesion of fibrolytic microbiota and the activity of the enzymes involved in cellulose hydrolysis (Jenkins, 1993). Except for a linear reduction $(\mathrm{P}=0.0254)$ in the rumen butyrate content, the cows' rumen environments were not 
altered by $\mathrm{SO}$ and can be considered adequate $(\mathrm{pH}$ $>6.0$ and $\mathrm{N}_{-} \mathrm{NH}_{3}$ level $>10 \mathrm{mg} \mathrm{dL}^{-1}$; Table 4) for fermentation of fibrous carbohydrates (Valadares \& Pina, 2011). Furthermore, the similarity $(\mathrm{P}>0.05)$ in degradability parameters for NDF (Table 3 ) and rumen acetate content (Table 4) demonstrated that the ruminal digestion of the dietary fibrous fractions were not affected by SO.

The diets were isoproteic (Table 1) with similar DM intake (Table 2), and thus, there was no effect of SO on CP intake (Table 2). Additionally, there were no effects on nitrogen metabolism, i.e., $\mathrm{CP}$ apparent digestibility (Table 2), rumen $\mathrm{N}-\mathrm{NH}_{3}$ content (Table 4), MUN (Table 5), and serum urea nitrogen (Table 6). As expected, the replacement of ground corn and citrus pulp by $\mathrm{SO}$, rich in fat, linearly increased $(\mathrm{P}<0.0001)$ the EE intake (Table 2). Relative to the control treatment, EE intake increased by $97 \%$, $184 \%$, and $240 \%$ in the diets with 15,30 , and 45 $\mathrm{g} \mathrm{kg}^{-1} \mathrm{SO}$, respectively. The linear increase in TDN $(\mathrm{P}=0.0032)$ in response to $\mathrm{SO}$ is a consequence of the replacement of carbohydrate sources (ground corn and citrus pulp) by fat (SO) with a 2.25 -fold greater energy content. The EE digestibility also increased with SO (Table 2). Similar results were obtained in the productive performance trial (Souza et al., 2019).

The most consumed FAs were linoleic and oleic acids (Table 2). Relative to the control treatment, SO increased linoleic acid intake by $154 \%, 301 \%$, and $335 \%$, and oleic acid intake by $101 \%, 180 \%$, and $185 \%$ for the diets with 15,30 , and $45 \mathrm{~g} \mathrm{~kg}^{-1}$ $\mathrm{SO}$, respectively. None of the dietary ingredients are an important source of $\alpha$-linolenic acid (Souza et al., 2019), and thus, the intake of this FA was low (Table 2). $\alpha$-Linolenic and linoleic acid, together with oleic acid, are the main substrates for the formation of vaccenic acid in the rumen by partial biohydrogenation $(\mathrm{BH})$ reactions (Shingfield, Bernard, Leroux, \& Chilliard, 2010). In the mammary gland, vaccenic acid is the precursor for the synthesis of $70-95 \%$ of all rumenic acid secreted in bovine milk (Kliem \& Shingfeld, 2016; Prado,
Schmidely, Nozière, \& Ferlay, 2019). Furthermore, approximately $25 \%$ of the vaccenic acid uptake is desaturated into rumenic acid in the mammary gland (Prado et al., 2019).

The absence of an effect $(\mathrm{P}>0.05)$ of $\mathrm{SO}$ on milk yield (Table 5) can be interpreted as a reflection of the similarities $(\mathrm{P}>0.05)$ in DM and TDN intake (Table $2)$. These data corroborate the results of Souza et al. (2019) in the productive performance trial. The linear increase in milk protein content $(\mathrm{P}=0.0242)$ promoted by SO supports the results from some studies (Rodney, Celi, Scott, Breinhild, \& Lean, 2015; Lopes et al., 2019), although the literature commonly indicates that lipid supplementation of diets supplied to cows reduces milk protein content (NRC, 2001; Mahdavi, Mahdavi, Darabighane, Mead, \& Lee, 2019). The linear reduction in milk fat content was proportionally higher than the linear increase in milk protein content. These changes promoted a linear decrease in milk total solids content because the milk lactose content was not altered by SO (Table 5). Relative to the control treatment, the $45 \mathrm{~g} \mathrm{~kg}^{-1} \mathrm{SO}$ diet decreased milk fat content by $29 \%$ and slightly increased milk protein content by $6 \%$ (Table 5). However, the linear reductions in milk protein $(\mathrm{P}=0.0242)$ and total solids $(\mathrm{P}=0.0046)$ contents were not sufficient to promote a difference among treatments $(\mathrm{P}>0.05)$ in their daily yields (Table 5). Consistent with the absence of a treatment effect on milk yield and lactose content $(\mathrm{P}>0.05)$, there was no difference in the daily yield of this component. The absence of an SO-mediated effect on milk lactose content (Table $5)$ may be a reflection of the similarity $(\mathrm{P}>0.05)$ observed among treatments in rumen propionate concentrations (Table 4) and serum glucose content (Table 6).

The negative effect of the dietary inclusion of vegetable oils on cow's milk fat content is well documented in the literature (C. G. S. Ribeiro et al., 2018; Lopes et al., 2019; Mahdavi et al., 2019; Rodrigues et al., 2019). Additionally, the current results corroborate Souza et al. (2019) 
in the productive performance trial. The milk fat depression (MFD) observed in the present study can be explained by the linear increase $(\mathrm{P}<0.05)$ in the omasal digesta (Table 7) and milk fat (Tables 8 and 9) contents of known FA intermediates of ruminal $\mathrm{BH}$, associated with the inhibition of lipogenesis in the cow mammary gland, i.e., trans-10 C18:1, trans-10, cis-12 CLA, and trans-9, cis-11 CLA (Shingfield et al., 2010; Bernard et al., 2018; Prado et al., 2019). SO promoted a linear increase in omasal digesta trans-10 $\mathrm{C} 18: 1$ content $(\mathrm{P}=0.0124)$ and milk fat trans-10 C18:1 ( $\mathrm{P}=0.0076)$, trans-10, cis-12 CLA ( $\mathrm{P}=0.0015)$, and trans-9, cis-11 CLA $(\mathrm{P}=0.0018)$ contents. The regressions $(\mathrm{P}<0.05)$ obtained between the milk fat content (y; \%) versus omasal digesta content ( $\mathrm{x}$; g 100 $10 \mathrm{~g}^{-1} \mathrm{FA}$ ) of trans-10 $\mathrm{C} 18: 1(\hat{\mathrm{y}}=-0.08765 \mathrm{x}+3.40627)$ and trans -10 , cis$12 \operatorname{CLA}(\hat{\mathrm{y}}=-2.01162 \mathrm{x}+3.56039)$ and versus the milk fat content (x; g 100-1 g FA) of trans-10 C18:1 $(\hat{\mathrm{y}}=-0.16257 \mathrm{x}+3.31715)$, trans -10 , cis-12 CLA $(\hat{\mathrm{y}}$ $=-6.66674 \mathrm{x}+3.49271)$, and trans-9, cis-11 CLA $(\hat{y}=-8.5327 x+3.67960)$ demonstrated the effect of these FAs, which are considered to be MFD markers.

Relative to the control treatment, the $45 \mathrm{~g} \mathrm{~kg}^{-1}$ SO diet impressively increased the trans-10 C18:1 content in omasal digesta (Table 7) and milk fat (Table 9) 1,051\% and 980\%, respectively. These data indicate that the trans-10 BH pathway of linoleic acid was activated and intensively performed by the ruminal microbiota. The shift from the trans-11 to the trans-10 alternative BH pathway of linoleic acid is typical of diets supplemented with vegetable oils rich in polyunsaturated FAs (PUFAs). This correlates with changes in the rumen environment, microbial populations, and the amount and type of available FA and carbohydrate substrates (Rico et al., 2015a). Despite the absence of an SO effect on rumen $\mathrm{pH}(\mathrm{P}>0.05)$, on average, greater than 6.0 for all treatments (Table 4), the $\mathrm{pH}$ remained below 6.0 from 6 to $17 \mathrm{~h}$ after ration provision (Figure 1). In diets with high PUFA levels, this factor is particularly important because the main microorganisms responsible for the $\mathrm{BH}$ processes of these FAs are fibrolytic bacteria that are sensitive to low pH conditions (Rico, Preston, Risser, \& Harvatine, 2015b). A decreased ruminal $\mathrm{pH}$ alters the microbial population (e.g., cellulolytic bacteria) and $\mathrm{BH}$ pathways. Consequently, the formation of trans-10 18:1 and trans-10, cis-12 CLA is increased (Fuentes, Calsamiglia, Cardozo, \& Vlaeminck, 2009).

The inhibitory effects of trans-10, cis-12 CLA, trans-9, cis-11 CLA, and trans-10 C18:1 on MFD are associated with the reduction in de novo FA synthesis in the mammary gland (Bernard et al., 2018; Prado et al., 2019). The alteration in ruminal fermentation that results in inadequate production of acetate and butyrate to support milk fat synthesis is one theory to explain the mechanism that underlies MFD (Fuentes et al., 2009). In the present study, the rumen acetate content was unchanged by $\mathrm{SO}$, while slight reductions in the rumen butyrate content did not appear to be sufficient to promote the observed MFD. It is likely that unique FAs produced as a result of alterations in the classical linoleic acid $\mathrm{BH}$ pathway promoted the inhibition of mammary milk fat synthesis. The high negative correlations $(\mathrm{P}<0.05)$ between the milk fat trans-10 18:1, trans-10, cis-12 CLA, and trans-9, cis-11 CLA contents versus de novo-synthesized C4:0 to $\mathrm{C} 16: 0$ FAs $(\mathrm{r}=-0.55,-0.70$ and -0.73 , respectively) indicate that these FAs did in fact inhibit lipogenesis in the mammary gland by reducing de novo FA synthesis (Bernard et al., 2018). Therefore, in response to $\mathrm{SO}$, the reduction in the milk fat C4:0 to C16:0 contents (Table 8), which was positively correlated with milk fat content $(\mathrm{r}=0.72$; $\mathrm{P}=0.0018$ ), significantly promoted MFD. Another factor that may have contributed to the reduction in the milk fat content of de novo-synthesized FAs is the high C18 FA supply to the mammary gland. This phenomenon may modify C18 FA uptake and thus increase competition with short-chain FAs for esterification into the triglycerides of milk fat (Shingfield et al., 2010; Prado et al., 2019). This 
hypothesis is supported by negative correlations ( $\mathrm{r}$ $=-0.55$ to $-0.93, \mathrm{P}<0.03$ ) between the sum of the milk fat $\mathrm{C} 4: 0$ to $\mathrm{C} 16: 0$ contents versus the milk fat contents of several C18-unsaturated FAs (e.g., oleic and rumenic acid, cis-9, trans-12 C18:2, trans-4 $\mathrm{C} 18: 1$ to trans-16 $\mathrm{C} 18: 1$, cis-11 $\mathrm{C} 18: 1$, cis-12 C18:1, trans-9, cis-11 CLA, and trans-10, cis-12 CLA). The negative effect of SO on the milk fat content of de novo-synthesized FAs has also been observed in the productive performance trial (Souza et al., 2019) and in other studies (C. G. S. Ribeiro et al., 2018; Lopes et al., 2019).

The diets in the present study were isofibrous, with an average of $313 \mathrm{~g} \mathrm{~kg}^{-1} \mathrm{NDF}_{\text {ap }}$. However, the $\mathrm{SO}$-supplemented diets presented lower $\mathrm{NFC}_{\text {ap }}$ and higher EE levels (Table 1) due to the replacement of citrus pulp and ground corn with SO. In response to the lower fermentability of the SO diets, there were linear reductions $(\mathrm{P}<0.05)$ in the milk fat content of the major OBCFAs (Table 8). These FAs are found in the lipid membranes of ruminal bacteria and originate from the digestion and absorption of lipids synthesized by the ruminal bacteria, as well as from de novo synthesis in the mammary gland (Kliem \& Shingfield, 2016). Differences in sensitivity to rumen $\mathrm{pH}$ and PUFAs among species and communities of ruminal bacteria may also have contributed to the reduction in milk fat OBCFA content (Rico et al., 2015b). There were consistent negative correlations $(\mathrm{P}<0.01)$ between the milk fat OBCFA content and intakes of EE $(r=-0.87)$ and of oleic, linoleic, and $\alpha$-linolenic acids $(r=-0.70$ to $-0.83)$. Although the major omasal digesta OBCFA contents were similar $(\mathrm{P}>0.05)$ among diets (Table 7), the milk fat contents of odd linear-chain FAs and OBCFAs were dependent on their respective omasal digesta content $(\mathrm{r}=0.59, \mathrm{P}=0.0159$, and $\mathrm{r}=0.63, \mathrm{P}=0.0096$, respectively). This finding indicates that the milk secretion of these FAs was partly ruminal in origin and partly arose from de novo mammary synthesis (Prado et al., 2019). Among the OBCFAs, iso C15:1 was the only one considered to be a potential MFD marker due to its strong positive association with cows that secreted a typical milk fat content (Conte, Dimauro, Serra, Macciotta, \& Mele, 2018). Consistent with Conte et al. (2018), in the present study, among all OBCFAs, iso $\mathrm{C} 15: 0$ was the most proportionally reduced in milk fat (Table 8). Relative to the control treatment and considering the major OBCFAs, the $45 \mathrm{~g} \mathrm{~kg}^{-1}$ SO diet decreased the milk fat iso $\mathrm{C} 15: 0$, anteiso C15:0, C15:0, and C17:0 contents by $60 \%, 42 \%$, $35 \%$, and $19 \%$, respectively.

Corroborating the results obtained in the productive performance trial (Souza et al., 2019), the increased rumen unsaturated FA load, mainly linoleic acid (Table 2), promoted intense ruminal BH. This phenomenon can be verified by the reduction in apparent transfer into milk of ingested linoleic acid (Table 5), the impressive linear increases in the omasal digesta contents of several trans-C18:1 FAs (Table 7), and in the milk fat contents of stearic acid (Table 8), trans-C18:1 FAs, and conjugated and nonconjugated isomers of linoleic acid (Table 9). Additionally, the absence of an SO effect $(\mathrm{P}>0.05)$ on the omasal digesta linoleic acid content (Table 7), despite increases in the intake of this FA in SO diets (Table 2), supports the hypothesis that there was intense $\mathrm{BH}$ in the rumen. Due to the high rumen linoleic acid load, the maximum capacity of the trans-11 rumen $\mathrm{BH}$ pathway was reached at $31.8 \mathrm{~g} \mathrm{~kg}^{-1} \mathrm{SO}$ as indicated by the quadratic effect of SO $(\mathrm{P}=0.0198)$ on the omasal digesta vaccenic acid content. This phenomenon (Table 7) triggered the need for the microbiota to activate the trans-10 alternative ruminal linoleic acid BH pathway. The ratio of trans-11 C18:1/trans-10 C18:1 FAs in the omasal digesta was numerically decreased $(\mathrm{P}=0.0616)$, data that indicate a shift from the trans-11 to trans-10 ruminal BH pathway of linoleic acid. Relative to the control treatment, the $45 \mathrm{~g}$ $\mathrm{kg}^{-1}$ SO diet decreased that ratio by $49 \%$ (Table 7). The accumulation of trans-C18:1 FAs, especially vaccenic acid, trans-10 C18:1, and elaidic acid, in the omasal digesta occurred at the expense of stearic acid, whose omasal digesta content was 
unchanged by SO (Table 7). This finding partially indicates a reduction in the final step of rumen $\mathrm{BH}$ of unsaturated $\mathrm{C} 18$ FAs. Reductions $(\mathrm{P}<0.05)$ in the omasal digesta ratios of stearic/vaccenic acid and stearic/trans-10 C18:1 acid (Table 7) can also be considered indicative of this phenomenon. All changes in omasal digesta FA contents were due to adaptations and changes in the rumen microbiome in response to the unsaturated FA load. However, further investigation is needed to elucidate the functional role of specific bacterial populations in the process of modification of dietary lipids (Rico et al., 2015b).

SO promoted pronounced linear increases $(\mathrm{P}<0.01)$ in the milk fat content of all trans-C18:1 FAs, including elaidic acid, trans-10 C18:1, and vaccenic acid (Table 9). The omasal digesta concentrations of all trans-C18:1 FAs were correlated with their appearance in milk $(\mathrm{r}=0.51$ to 0.68 ; $\mathrm{P}<0.05$ ) except for trans-10 $\mathrm{C} 18: 1$, whose omasal digesta content was much higher than its milk fat content. There were marked increases in the milk fat elaidic acid, trans-10 C18:1, vaccenic acid, and total trans-C18:1 FA contents of $317 \%$, $980 \%, 746 \%$ and $665 \%$, respectively, in the 45 $\mathrm{g} \mathrm{kg}^{-1} \mathrm{SO}$ compared to the control diet (Table 9). These results support those of the productive performance trial (Souza et al., 2019). Elaidic acid and trans-10 $\mathrm{C} 18: 1$ are associated with deleterious effects on cardiovascular health (Vahmani et al., 2017); therefore, an increase in the levels of these FAs in milk fat is not desirable for human nutrition.

Rumenic acid has beneficial effects on human health including decreasing the risk of cancer and type 2 diabetes and improving the immune system (Yang et al., 2015). Diets that promote an increase in the supply of vaccenic acid from the rumen to the mammary gland generally lead to higher rumenic acid levels in milk. This FA is the precursor for the synthesis of $70-95 \%$ of rumenic acid in bovine milk (Kliem \& Shingfeld, 2016; Prado et al., 2019). This potential is corroborated by the positive relationship ( $\left.\hat{\mathrm{y}}=0.23468 \mathrm{x} ; \mathrm{r}_{\text {adj }}{ }=0.79 ; \mathrm{P}<0.0001\right)$ between rumenic acid milk fat content (y; g $100 \mathrm{~g}^{-1}$ FA) versus omasal digesta vaccenic acid content (x; g $100 \mathrm{~g}^{-1}$ FA). SO increased the omasal digesta vaccenic acid content (Table 7) as shown by the regressions $(\mathrm{P}<0.0001)$ between the omasal digesta content of vaccenic acid (y; g $100 \mathrm{~g}^{-1} \mathrm{FA}$ ) versus intakes $\left(\mathrm{x} ; \mathrm{g}\right.$ cow $^{-1}$ day $\left.^{-1}\right)$ of oleic $\left(\hat{y}=0.05008^{*} \mathrm{x}\right.$; $\left.\mathrm{r}^{2}{ }_{\text {adj }}=0.80\right)$, linoleic $\left(\hat{\mathrm{y}}=0.02034 * \mathrm{x} ; \mathrm{r}^{2}{ }_{\text {adj }}=0.79\right)$ and $\alpha$-linolenic acids $\left(\hat{y}=0.41786 * x ; r^{2}{ }_{\text {adj }}=0.77\right)$. The milk fat rumenic acid contents obtained from 30-45 $\mathrm{g} \mathrm{kg}^{-1}$ SO diets (Table 9) were higher compared to the range of 0.56-2.05 g $100 \mathrm{~g}^{-1}$ FA reported for cows fed diets based on 400-630 $\mathrm{g} \mathrm{kg}^{-1}$ sugarcane with lipid supplementation (Meneses et al., 2015; Rodrigues et al., 2019). In the productive performance trial, Souza et al. (2019) obtained higher milk fat rumenic acid contents in all SO diets, i.e., 1.46, 2.41, and

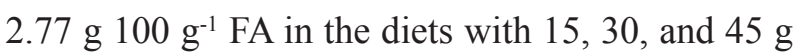
$\mathrm{kg}^{-1} \mathrm{SO}$, respectively. Except for the $45 \mathrm{~g} \mathrm{~kg}^{-1} \mathrm{SO}$ diet, higher milk fat vaccenic acid contents were also obtained by Souza et al. (2019), i.e., 3.35, 6.40

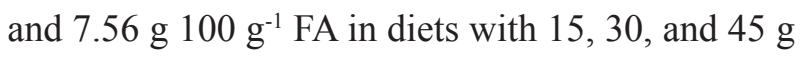
$\mathrm{kg}^{-1} \mathrm{SO}$, respectively. The lower milk rumenic acid contents in the present study can be attributed, at least partly, to the lower milk vaccenic acid contents in association with the lower enzymatic activity of stearoyl-CoA desaturase (SCD) in the rumenic/ vaccenic FA pair compared to those presented by Souza et al. (2019). In both studies, SO promoted a linear reduction in SCD activity for the rumenic/ vaccenic FA pair.

Some FAs (e.g., trans-10 C18:1 and trans-10, cis12 CLA) were associated with a decrease in SCDcatalyzed FA desaturation in the bovine mammary gland (Kadegowda, Bionaz, Piperova, Erdman, \& Loor, 2009). However, in the present study, none of the correlations between the milk fat content of trans-10 C18:1 and trans-10, cis-12 CLA versus all the SCD indices were significant $(\mathrm{P}>0.05)$. On the other hand, there were negative correlations $(\mathrm{P}<0.05)$ between SCD activity for rumenic/ vaccenic versus specific FAs (stearic acid, cis-13 C18:1, trans-16 C18:1, C20:0, and C24:0). Stearic 
acid is a substrate that competes with vaccenic acid for SCD in oleic acid synthesis. Stearic acid showed a high negative correlation with SCD activity for the rumenic acid/vaccenic acid pair $(\mathrm{r}=-0.79$; $\mathrm{P}=0.0003)$. A linear increase $(\mathrm{P}=0.0074)$ in the milk fat oleic acid content was observed in SO treatments (Table 8).

The absence of an SO effect on serum glucose content (Table 6) corroborates the results obtained in the productive performance trial (Souza et al., 2019) and those presented by Rodrigues et al. (2017, 2019). No SO effect on serum NEFA contents was observed, data that are consistent with the results presented by Rodrigues et al. (2019). The obtained values (Table 6) were within the normal range for healthy cows, $<0.4 \mathrm{mmol} \mathrm{L}^{-1}$ (J. E. P. Santos, 2011). The increase in serum cholesterol and triglycerides would be expected due to increased FA transport in the blood in response to supplementation with vegetable oils (Rodrigues et al., 2017, 2019; Souza et al., 2019). For serum cholesterol content, this increase was observed $(\mathrm{P}<0.05)$. Despite the absence of a treatment effect $(\mathrm{P}>0.05)$ on serum triglycerides, the SO diets promoted numerically higher values compared to the control (Table 6).

Corroborating the results obtained in the productive performance trial (Souza et al., 2019), SO improved the indices of nutritional quality for milk fat: AI, TI, and the $\mathrm{h} / \mathrm{H}$ FA ratio (data not shown). There were linear decreases $(\mathrm{P}<0.01)$ in milk fat hypercholesterolemic FAs (lauric, myristic and palmitic acids) and a linear increase $(\mathrm{P}=0.0074)$ in milk fat oleic acid (Table 8), a FA associated with beneficial effects on cardiovascular health (Hammad, Pu, \& Jones, 2016).

\section{Conclusions}

Up to $45 \mathrm{~g} \mathrm{~kg}^{-1}$ sunflower oil can be included on dry matter of chopped sugarcane-based diets without reducing consumption, apparent digestibility and rumen degradability of dry matter and fiber.
Supplementing chopped sugarcane-based diets with 30 to $45 \mathrm{~g} \mathrm{~kg}^{-1}$ sunflower oil (dry matter basis) promotes milk fat depression due to the inhibition of mammary lipogenesis by specific rumen-derived fatty acid intermediates in the biohydrogenation of unsaturated $\mathrm{C} 18$ fatty acids.

The inclusion of 15 to $45 \mathrm{~g} \mathrm{~kg}^{-1}$ sunflower oil in chopped sugarcane-based diets improves the nutritional quality of milk fat, with increases in the levels of oleic, vaccenic and rumenic acids, which are beneficial to human health, and reductions in the levels of hypercholesterolemic lauric, myristic and palmitic acids.

\section{Acknowledgments}

The authors gratefully acknowledge the Fundação de Amparo à Pesquisa de Minas Gerais (Fapemig), Conselho Nacional de Desenvolvimento Científico e Tecnológico (CNPq) and Embrapa Dairy Cattle for scholarships and for financial support of this study. We would also like to thank the technicians Ernando Ferreira Motta and Hernani Guilherme Barbosa Filho, who performed the analyses of fatty acid composition at the Laboratory of Chromatography of Embrapa Dairy Cattle.

\section{References}

Bernard, L., Bonnet, M., Delavaud, C., Delosière, M., Ferlay, A., Fougère, H., \& Graulet, B. (2018). Milk fat globule in ruminant: major and minor compounds, nutritional regulation and differences among species. European Journal of Lipid Science and Technology, 120(5), 1700039. doi: 10.1002/ejlt.201700039

Campos, M. M., Lopes, F. C. F., Pereira, L. G. R., Machado, F. S., \& Tomich, T. R. (2017). Cana-deaçúcar na alimentação de rebanhos leiteiros. In F. C. Silva, B. J. R. Alves, \& P. L. Freitas (Org.), Sistema de produção mecanizada da cana-de-açúcar integrada à produção de energia e alimentos (pp. 900-938). Brasília: EMBRAPA.

Conte, G., Dimauro, C., Serra, A., Macciotta, N. P. P., \& Mele, M. (2018). A canonical discriminant analysis to study the association between milk fatty acids of 
ruminal origin and milk fat depression in dairy cows. Journal of Dairy Science, 101(7), 6497-6510. doi: 10.3168/jds.2017-13941

Detmann, E., Valadares, S. C., F ${ }^{\circ}$., Berchielli, T. T., Cabral, L. S., Ladeira, M. M., Souza, M. A.,... Azevedo, J. A. G. (2012). Métodos para análise de alimentos. Visconde do Rio Branco: SUPREMA.

Fuentes, M. C., Calsamiglia, S., Cardozo, P. W., \& Vlaeminck, B. (2009). Effect of $\mathrm{pH}$ and level of concentrate in the diet on the production of biohydrogenation intermediates in a dual-flow continuous culture. Journal of Dairy Science, 92(9), 4456-4466. doi: 10.3168/jds.2008-1722

Hammad, S., Pu, S., \& Jones, P. J. (2016). Current evidence supporting the link between dietary fatty acids and cardiovascular disease. Lipids, 51(5), 507517. doi: 10.1007/s11745-015-4113-X

Jenkins, T. C. (1993). Lipid metabolism in the rumen. Journal of Dairy Science, 76(1), 3851-3863. doi: 10.3168/jds.S0022-0302(93)77727-9

Kadegowda, A. K. G., Bionaz, M., Piperova, L. S., Erdman, R. A., \& Loor, J. J. (2009). Peroxisome proliferator-activated receptor- $\gamma$ activation and longchain fatty acids alter lipogenic gene networks in bovine mammary epithelial cells to various extents. Journal of Dairy Science, 92(9), 4276-4289. doi: 10.3168/jds.2008-1932

Kliem, K. E., \& Shingfield, K. J. (2016). Manipulation of milk fatty acid composition in lactating cows: opportunities and challenges. European Journal of Lipid Science and Technology, 118(11), 1661-1683. doi: 10.1002/ejlt.201400543

Leão, M. I. (2002). Metodologias de coletas de digestas omasal e abomasal em novilhos submetidos a três níveis de ingestão: consumo, digestibilidade $e$ produção microbiana. Tese de doutorado, Universidade Federal de Minas Gerais, Belo Horizonte, MG, Brasil.

Lopes, F. C. F., Ribeiro, C. G. S., Rodriguez, N. M., Gama, M. A. S., Morenz, M. J. F., Antoniassi, R., \& Bizzo, H. R. (2019). Butter fatty acid composition as a function of soybean oil supplementation and time of milking, and performance of Holstein x Gyr cows fed with chopped elephant grass-based diets. Semina: Ciências Agrárias, 40(5), 2027-2044. doi: 10.5433/1679-0359.2019v40n5p2027

Mahdavi, A., Mahdavi, A., Darabighane, B., Mead, A., \& Lee, M. R. F. (2019). Effects of soybean oil supplement to diets of lactating dairy cows, on productive performance, and milk fat acids profile: a meta-analysis. Italian Journal of Animal Science, 18(1), 809-819. doi: 10.1080/1828051X.2019. 1585211

Meneses, M. A., Silva, F. F., Silva, R. R., Schio, A. R., Silva, G. M., Rodrigues, E. S. O.,... Pimentel, L. R. (2015). Composição em ácidos graxos do leite de vacas alimentadas com glicerina de baixa pureza. Semina: Ciências Agrárias, 36(2), 971-984. doi: 10.5433/1679-0359.2015v36n2p971

National Research Council (2001). Nutrients requirements of dairy cattle (7nd ed.). Washington: National Academy Press.

Nocek, J. E. (1988). In situ and other methods to estimate ruminal protein and energy digestibility. A review. Journal of Dairy Science, 71(8), 2051-2069. doi: 10.3168/jds.S0022-0302(88)79781-7

Ørskov, E. R., \& McDonald, I. (1979). The estimation of protein degradability in the rumen from incubation measurements weighted according to rate of passage. The Journal of Agricultural Science, 92(2), 499-503. doi: $10.1017 / \mathrm{S} 0021859600063048$

Prado, L. A., Schmidely, P., Nozière, P., \& Ferlay, A. (2019). Milk saturated fatty acids, odd- and branchedchain fatty acids, and isomers of C18:1, C18:2, and C18:3n-3 according to their duodenal flows in dairy cows: A meta-analysis approach. Journal of Dairy Science, 102(4), 3053-3070. doi: 10.3168/jds.201815194

Ribeiro, C. G. S., Lopes, F. C. F., Gama, M. A. S., Rodriguez, N. M., \& Morenz, M. J. F. (2018). Ruminal fermentation and degradation, kinetic flow of the digesta and milk fatty acid composition of cows fed chopped elephant grass supplemented with soybean oil. Semina: Ciências Agrárias, 39(4), 17751794. doi: 10.5433/1679-0359.2018v39n4p1775

Ribeiro, R. C. O., Villela, S. D. J., Valadares, S. C., Fo Santos, S. A., Ribeiro, K. G., Detmann, E.,... Martins, P. G. M. A. (2015). Effects of roughage sources produced in a tropical environment on forage intake, and ruminal and microbial parameters. Journal of Animal Science, 93(5), 2363-2374. doi: 10.2527/ jas.2014-8719

Rico, D. E., Holloway, A. W., \& Harvatine, K. J. (2015a). Effect of diet fermentability and unsaturated fatty acid concentration on recovery from diet-induced milk fat depression. Journal of Dairy Science, 98(11), 7930-7943. doi: 10.3168/jds.2014-8990

Rico, D. E., Preston, S. H., Risser, J. M., \& Harvatine, K. J. (2015b). Rapid changes in key ruminal microbial populations during the induction of and recovery 
from diet-induced milk fat depression in dairy cows. British Journal of Nutrition, 114(3), 358-367. doi: 10.1017/S0007114515001865

Rodney, R. M., Celi, P., Scott, W., Breinhild, K., \& Lean, I. J. (2015). Effects of dietary fat on fertility of dairy cattle: A meta-analysis and meta-regression. Journal of Dairy Science, 98(8), 5601-5620. doi: 10.3168/ jds.2015-9528

Rodrigues, J. P. P., Paula, R. M., Rennó, L. N., Costa, G. P., Hamade, V. C. E., Valadares, S. C., F ${ }^{\circ}, \ldots$ Marcondes, M. I. (2019). Effects of soybean oil supplementation on performance, digestion and metabolism of early lactation dairy cows fed sugarcane-based diets. Animal, 13(6), 1198-1207. doi: $10.1017 / \mathrm{S} 1751731118002781$

Rodrigues, J. P. P., Paula, R. M., Rennó, L. N., Fontes, M. M. S., Machado, A. F., Valadares, S. C., F ${ }^{\mathrm{o}}, \ldots$ Marcondes, M. I. (2017). Short-term effects of soybean oil supplementation on performance, digestion, and metabolism in dairy cows fed sugarcane-based diets. Journal of Dairy Science, 100(6), 4435-4447. doi: 10.3168/jds.2016-11725

Santos, J. E. P. (2011). Distúrbios metabólicos. In T. T. Berchielli, A. Vaz Pires, \& S. G. Oliveira (Eds.), Nutrição de ruminantes (2a ed., pp. 439-520). Jaboticabal: FUNEP.

Santos, S. A., Valadares, S. C., Fo, Detmann, E., Valadares, R. F. D., Ruas, J. R. M., \& Amaral, P. M. (2011). Different forage sources for F1 Holstein $\mathrm{X}$ Gir dairy cows. Livestock Science, 142(1-3), 48-58. doi: 10.1016/j.livsci.2011.06.017

Shingfield, K. J., Ahvenjärvi, S., Toivonen, V., Ärölä, A., Nurmela, K. V. V., Huhtanen, P., \& Griinari, J. M. (2003). Effect of dietary fish oil on biohydrogenation of fatty acids and milk fatty acid content in cows. Animal Science, 77(1), 165-179. doi: 10.1017/ S1357729800053765
Shingfield, K. J., Bernard, L., Leroux, C., \& Chilliard, Y. (2010). Role of trans fatty acids in the nutritional regulation of mammary lipogenesis in ruminants. Animal, 4(7), 1140-1166. doi: 10.1017/S17 51731110000510

Souza, S. M., Lopes, F. C. F., Valadares, S. C., F ${ }^{\mathrm{o}}$, Gama, M. A. S., Rennó, L. N., \& Rodrigues, J. P. P. (2019). Milk fatty acid composition of Holstein $x$ Gyr dairy cows fed sugarcane-based diets containing citrus pulp supplemented with sunflower oil. Semina: Ciências Agrárias, 40(4), 1663-1680. doi: 10.5433/1679-0359.2019v40n4p1663

Tomich, T. R., \& Sampaio, I. B. M. (2004). A new strategy for the determination of forage degradability with an in situ technique through the use of one fistulated ruminant. The Journal of Agricultural Science, 142(5), 589-593. doi: 10.1017/S0021859604004654

Vahmani, P., Meadus, W. J., Duff, P., Rolland, D. C., \& Dugan, M. E. R. (2017). Comparing the lipogenic and cholesterol genic effects of individual trans-18:1 isomers in liver cells. European Journal of Lipid Science and Technology, 119(3), 1600162. doi: 10.1002/ejlt.201600162

Valadares, S. C., Fº, \& Pina, D. S. (2011). Fermentação ruminal. In T. T. Berchielli, A. Vaz Pires, \& S. G. Oliveira (Eds.), Nutrição de ruminantes (2a ed., pp. 161-191). Jaboticabal: FUNEP.

Weiss, W. P. (1999). Energy prediction equations for ruminant feeds. Proceedings of Cornell Nutrition Conference for Feed Manufactorers, Ithaca, USA, 61

Yang, B., Chen, H., Stanton, C., Ross, R. P., Zhang, H., Chen, Y. Q., \& Chen, W. (2015). Review of the roles of conjugated linoleic acid in health and disease. Journal of Functional Foods, 15, 314-325. doi: 10.1016/j.jff.2015.03.050 
